\title{
J CRASH MODELLING FOR FOUR LANE DIVIDED INTERCITY HIGHWAY USING ANN
}

\author{
Ch. Anudeep Reddy ${ }^{1}$, Jella Sowjanya ${ }^{2}$, Dr. C. Naveen Kumar ${ }^{3}$ \\ E-Mail Id: anudeep286@gmail.com \\ ${ }^{1,2}$ M.Tech Student, Civil Engineering Department, V.N.R Vignana Jyothi Institute of Engineering and \\ Technology, Hyderabad, Telangana, India \\ ${ }^{3}$ Associate Professor, Civil Engineering Department, V.N.R Vignana Jyothi Institute of Engineering and \\ Technology, Hyderabad, Telangana, India
}

\begin{abstract}
In India the most commonly used mode of transport is by roads, annually India losses 3\% of its GDP to road accidents which is over $\$ 58,000$ million in terms of value. So, the safety is considered as the most important aspect in terms of Designing, Construction, Maintenance. Traffic is recognized as the major growing public health problem in India.

This study aims to develop a model for prediction of crash frequency using recent mathematical techniques. Thus, crash data of National Highway 65 from Hyderabad to Vijayawada is been considered from year 2013 to 2018. Model calibration is done in soft computing technique ANNin MATLABusing dependent parameter as crash count per segment per year and independent parameters as geometric characteristics like change in curvature, gradient, degree of curvature, and average traffic volume is considered along with the speed. From which the three network gives the best output results.
\end{abstract}

Keywords- Crash modeling, ANN, Levenberg -Marguardt (LM) and Bayesian Regulation (BR).

\section{INTRODUCTION}

Road traffic safety refers to the methods and measures used to prevent road users from being killed or seriously injured. Typical road users include: pedestrians, cyclists, motorist, vehiclepassengers, and passengers of on-road public transport. The basic strategy of a Safe System approach is to ensure that in the event of a crash, the impact energies remain below the threshold that are likely to produce either death or serious injury. This threshold will vary for different crash scenarios, depending upon the level of protection offered to the road users involved in crash.

A total of 4,64,910 road crashes have been recorded in the year 2017. Out of which fatalities are 1,47,913 and injuries are 4,70, 975. In terms of road categories, the National highways constitute of 1,41,466 of total road crashes. State highways and other roads accounted for 1,16,158 and 2,07,286 respectively. The results of road accidents may be great and its negative effect is treated no longer most effective on character fitness and welfare, but additionally at the economy. Consequently, avenue safety has come to be a trouble of country wide concern. So scientific analysis of road safety is an important aspect to improve roadway geometrics and vehicle conditions and also to provide hospital services for different cases in after the crash situation.

\section{LITERATURE REVIEW}

Development of crash prediction models is very important in the scientific analysis road safety, and in the past few years, researchers have proposed a number of analytical tools to analyze crash data. A number of independent variables that influence the frequency of crashes are mainly associated with driving behavior, road geometry, vehicle and environment. Crash count prediction models were developed first based on simple multiple linear regression models considering widely distributed errors. Nevertheless, researchers soon discovered that the frequency of a crash was more compatible with the Poisson distribution and therefore started using the Poisson regression model established by the advanced modelling technique called the Generalized Linear Models (GLM) instead of the traditional multiple linear regression technique [3]. Multivariate Poisson (MVP) regression models have been used for several decades and have become one of the most common modelling techniques in the field of road safety, particularly in the case of accident rate and accident frequency estimation. Several papers in the literature, such as [4]- [6] developed a MVP model to investigate the relationship between risk factors and accident rates. However, many researchers have found that the Poisson regression model has one major constraint, which is mean is equal to variance, the standard errors determined by the highest likelihood equation will be skewed and the sample results extracted from the experiment will be inaccurate. In overcoming the issue of over dispersion, researchersdevelopedthe Negative Binomial (NB) distribution (or Poisson-Gamma) rather than the Poisson distribution. Two models generalized linear model and the negative binomial regression were used to predict fatal accidents of the motor cyclists in Malaysia. Data was collected in the three states and for the period of three years.

Parameters such as fatal accidents, geometric features of the road and traffic census were used for developing these models. The study concluded that average number of motorcycles and number of access points on the roads significantly affect the fatalities of motor cyclists [7]. Different crash prediction models were developed using poison family regression models and Pearson's chi square test used to know the performance of the model.

$$
\begin{aligned}
& \text { www.ijtrs.com } \\
& \text { www.ijtrs.org }
\end{aligned}
$$




\section{J}

Explanatory variables like traffic volume, median openings, access roads, schools increase the crashes. The study concluded that Poisson Weibell model predicts with better accuracy [8].

Many statistical models were developed to study the effect of risk factors contributing the accident rate but their outputs are very complex to determine the correct results. To overcome this and to predict the model accurately some machine learning techniques like Artificial Neural Network and Support Vector Machine are used in some research papers for different road conditions $[9,10,11,12]$. However, their applications for Indian road conditions are very few and this paper examines the relationship between the risk contributing factors and accident and compares different model performances.

\section{MODEL DEVELOPMENT}

For the development of the crash frequency prediction model soft computing tool like artificial neural network is used.

\subsection{Artificial Neural Network}

An effective computing scheme is the Artificial Neural Network (ANN), whose main theme is the biologic neural networks analogy. ANN is also referred to as the "neural artificial system," or "processing systems that are distributed parallel" or "systems connectors." In order to permit communication between the units ANN acquires a large collection of units interconnections in a certain pattern. These units are simple, parallel processors also known as nodes or neurons.

Each neuron is linked by a connection link to other neurons. Every connection link is connected to a weight with input signal data. This is the most helpful data for neurons to resolve a certain issue, as weight generally excites or inhibits the signal. Each neuron has an inner state, which is called a signal for activation. The output signals generated after the input and activation rule have been combined can be transmitted to other units.

\subsection{Model of Artificial Neural Network}

The diagram below depicts the overall ANN model and its processing.

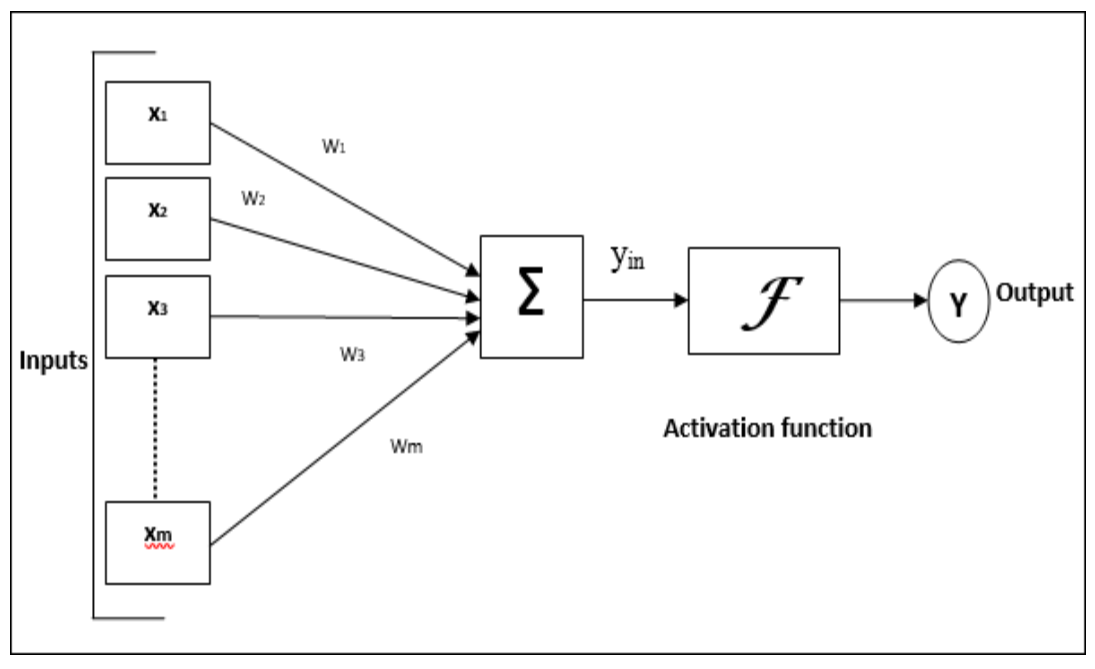

Fig. 3.1 ANN Model

\section{STUDY AREA}

The study area selected is a four-lane divided National Highway- 65, is a National Highway in India. It runs along the states of Maharashtra, Karnataka, Telangana and Andhra Pradesh. It starts at Pune and ends at Machilipatnam. Major cities on this route are Pune, Solapur, Hyderabad, Suryapet, Vijayawada and Machilipatnam. The length of highway is $926 \mathrm{kms}$ of which the study was conducted in between Hyderabad Vijayawada cities. The chainages 40+000 to 220+000 which is the selected study area. The operator and maintenance of this selected is controlled by the GMR Hyderabad Vijayawada Expressways Private Limited under BOT (Toll). There are three toll plaza's located in between the selected study location at $60+400,118+250,205+025$. The major places along the $\mathrm{NH}$ are chotuppal, chitralya, narketpally, nakrakal, suryapet, kodad, jagayapeta, nandigama.

Table-4.1 Road Infrastructures Details 


\begin{tabular}{|c|c|}
\hline T-Junctions & International Journal of Technical Research \& Science \\
\hline Median opening & 39 \\
\hline flyovers & 18 \\
\hline Toll plaza's & 03 \\
\hline Bridges & 01 \\
\hline
\end{tabular}

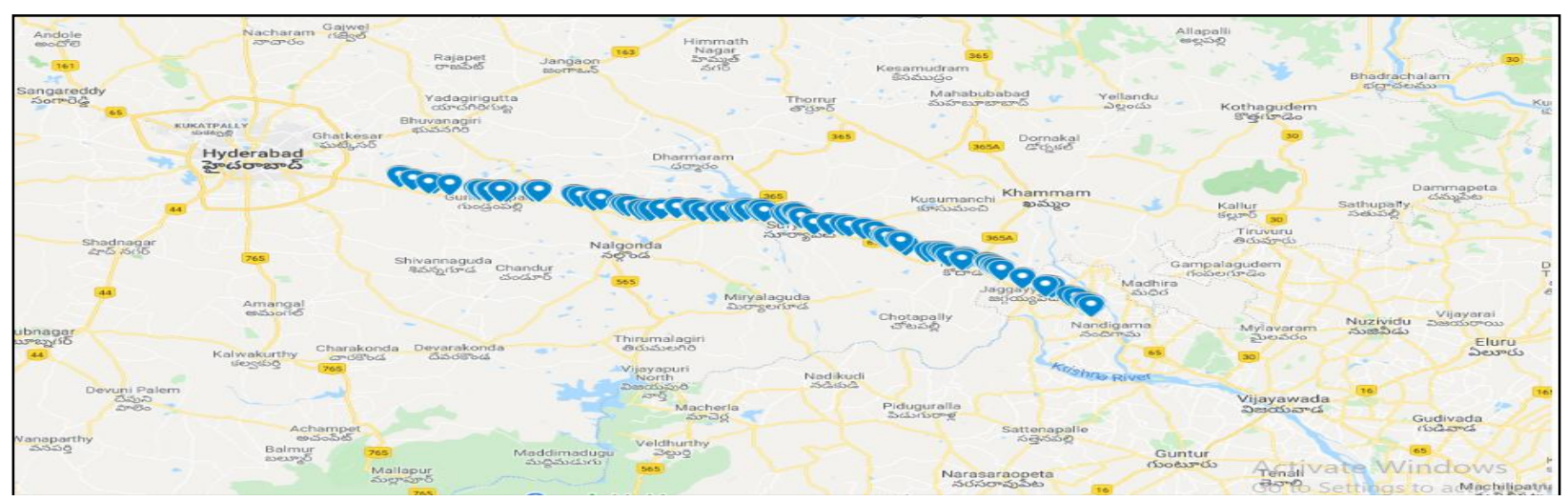

\subsection{Data Description}

Fig. 4.1Study Area Route Map of NH-65

The variables which influence the road safety are studied and the crash data was collected from GMR Hyderabad Vijayawada toll plazas for the period of five years from 2013 to 2018. Geometric parameters were extracted from the plan and profile drawings of the highway. These parameters include super elevation, horizontal radius, change in curvature, gradient. Traffic characteristics like traffic volume and speed are collected. Speed was collected using radar gun for the 15 major locations on highway for the both directions.

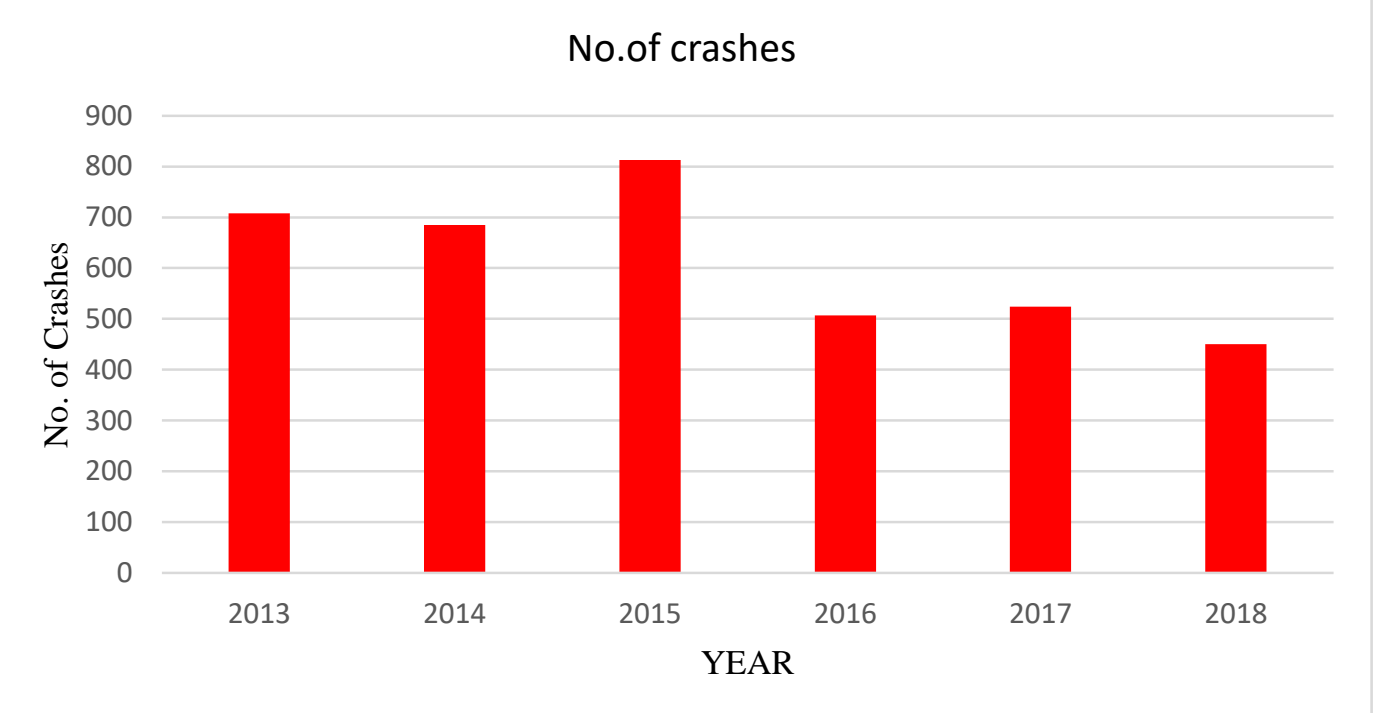

Fig 4.2 Graph with No. of Crashes vs Year

\section{ANALYSIS OF RESULTS}

The extracted data is used to develop the model and for easy calculation the data is normalized by applying natural logarithm.

The statistical summary of the parameters is tabulated in the table 5.1.

Table-5.1 Statistical Summary of the Parameters

\begin{tabular}{|c|c|c|c|}
\hline Parameters & Mean & Variance & Standard Deviation \\
\hline Volume & 9.562 & 0.082 & 0.286 \\
\hline
\end{tabular}

DOI Number: https://doi.org/10.30780/IJTRS.V05.I01.005

pg. 42

www.ijtrs.com

www.ijtrs.org

Paper Id: IJTRS-V4-I12-023 
ISSN No.: 2454- 2024 (online)

\begin{tabular}{|c|c|c|c|}
\hline Speed & 4.464 & 0.011 & 0.104 \\
\hline Gradient & 0.212 & 0.893 & 0.945 \\
\hline Superelevation & 1.979 & 7.061 & 2.657 \\
\hline K value & 4.488 & 3.490 & 1.868 \\
\hline Degree of curvature & 0.040 & 0.002 & 0.041 \\
\hline
\end{tabular}

Artificial neural network model is developed in MATLAB using neural network tool which is used to train, test and validate the dataset. The dataset is randomly divided for test, train and validation. $70 \%$ data is used for training, $15 \%$ is used for testing and $15 \%$ is used for validation. Input and target data are imported in the data manager tool box. The training algorithms used were Levenberg-Marguardt (LM) and Bayesian Regulation (BR). These training functions are used as the data set is very large. All network runs were carried out with the maximum epoch of 1000 . Six different network models were developed. Four models CFM1, CFM2, CFM3, CFM4 were developed using Bayesian Regulation (BR) with 3 layers and 10 neurons, 5 layers and 15 neurons, 5 layers and 30 neurons, 7 layers and 15 neurons respectively. CFM5 and CFM6 were created using Levenberg-Marguardt (LM) with 3 layers and 30 neurons, 5 layers and 30 neurons respectively. Number of layers and number of neurons were selected after conducting different experiments which gave better performance. The results and performance characteristics of the above developed models were tabulated in table 5.2. Out of all different models the Bayesian regulation gave the significant results with 5 layers and 30 neurons.

Table-5.2 Performance and Characteristics of the Models

\begin{tabular}{|c|c|c|c|c|c|c|c|c|c|}
\hline \multirow[t]{2}{*}{ Network } & \multirow[t]{2}{*}{ SBC } & \multirow[t]{2}{*}{$\begin{array}{l}\text { Training } \\
\text { function }\end{array}$} & \multirow[t]{2}{*}{ RMSE } & \multirow[t]{2}{*}{ MAD } & \multirow[t]{2}{*}{$\begin{array}{l}\text { Chi } \\
\text { Square }\end{array}$} & \multirow[t]{2}{*}{$\begin{array}{c}\text { Critical Chi } \\
\text { Square Value }\end{array}$} & \multicolumn{3}{|c|}{$\begin{array}{c}\text { Correlation coefficient } \\
\text { value }(\mathbf{R})\end{array}$} \\
\hline & & & & & & & Train & Test & All \\
\hline CFM1 & -0.23 & $\overline{B R}$ & 0.8871 & 0.0042 & 4521 & \multirow{6}{*}{5597} & 0.316 & 0.118 & 0.216 \\
\hline CFM2 & -0.10 & BR & 0.772 & 0.0056 & 4942 & & 0.216 & 0.04 & 0.118 \\
\hline CFM3 & -0.293 & BR & 0.221 & 0.003 & 4203.95 & & 0.538 & 0.151 & 0.414 \\
\hline CFM4 & -0.152 & BR & 0.431 & 0.0072 & 6221 & & 0.463 & 0.168 & 0.401 \\
\hline CFM5 & 0.211 & $\overline{\mathrm{LM}}$ & 0.551 & 0.0065 & 5436 & & 0.261 & 0.142 & 0.231 \\
\hline CFM6 & 0.245 & LM & 0.611 & 0.0054 & 6641 & & 0.231 & 0.004 & 0.16 \\
\hline
\end{tabular}
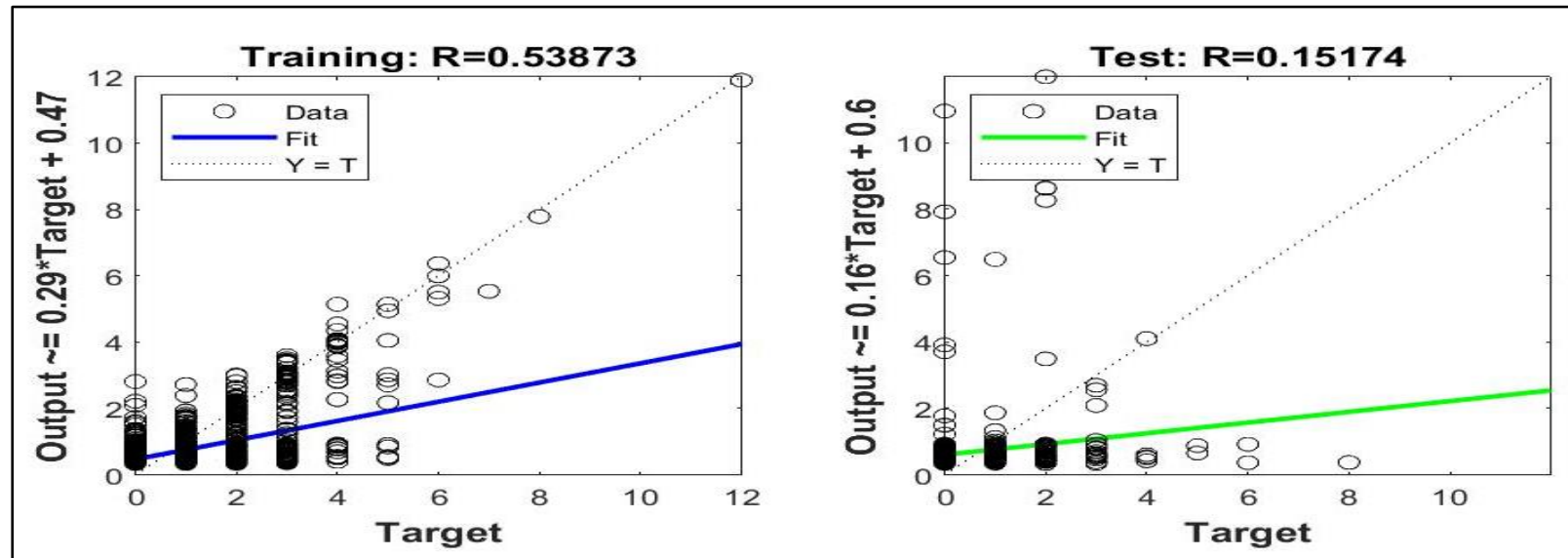


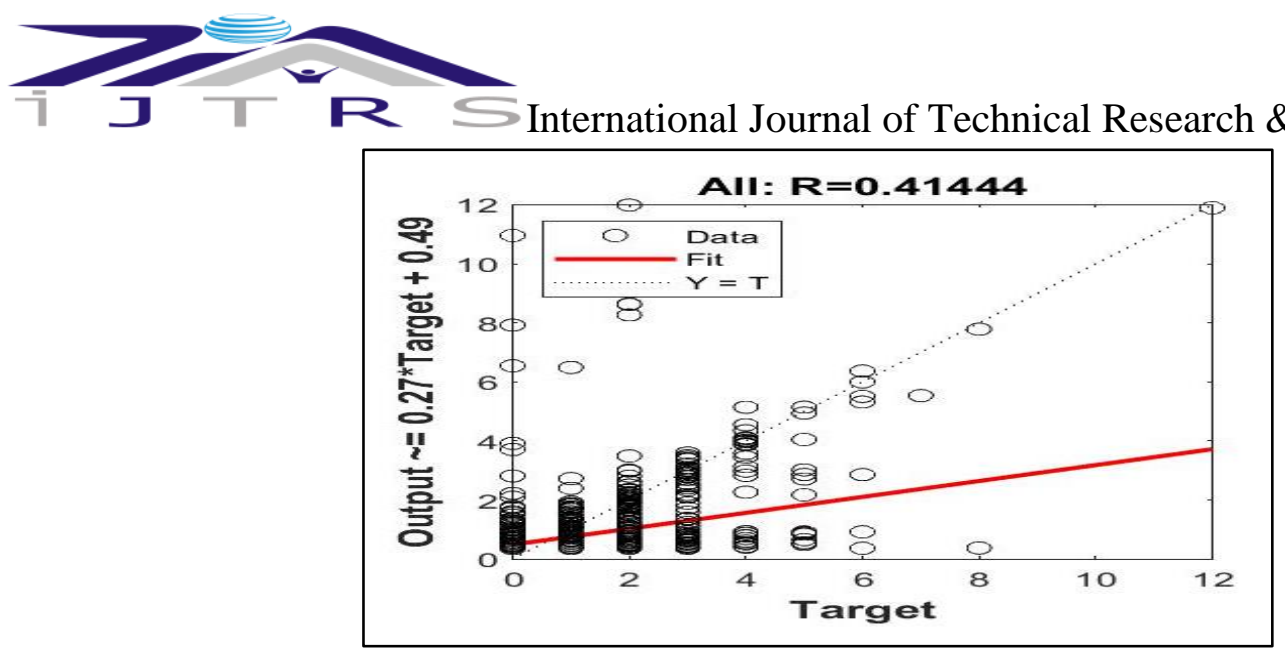

Fig. 5.1 Model for NH65: Crash Frequency Prediction Model
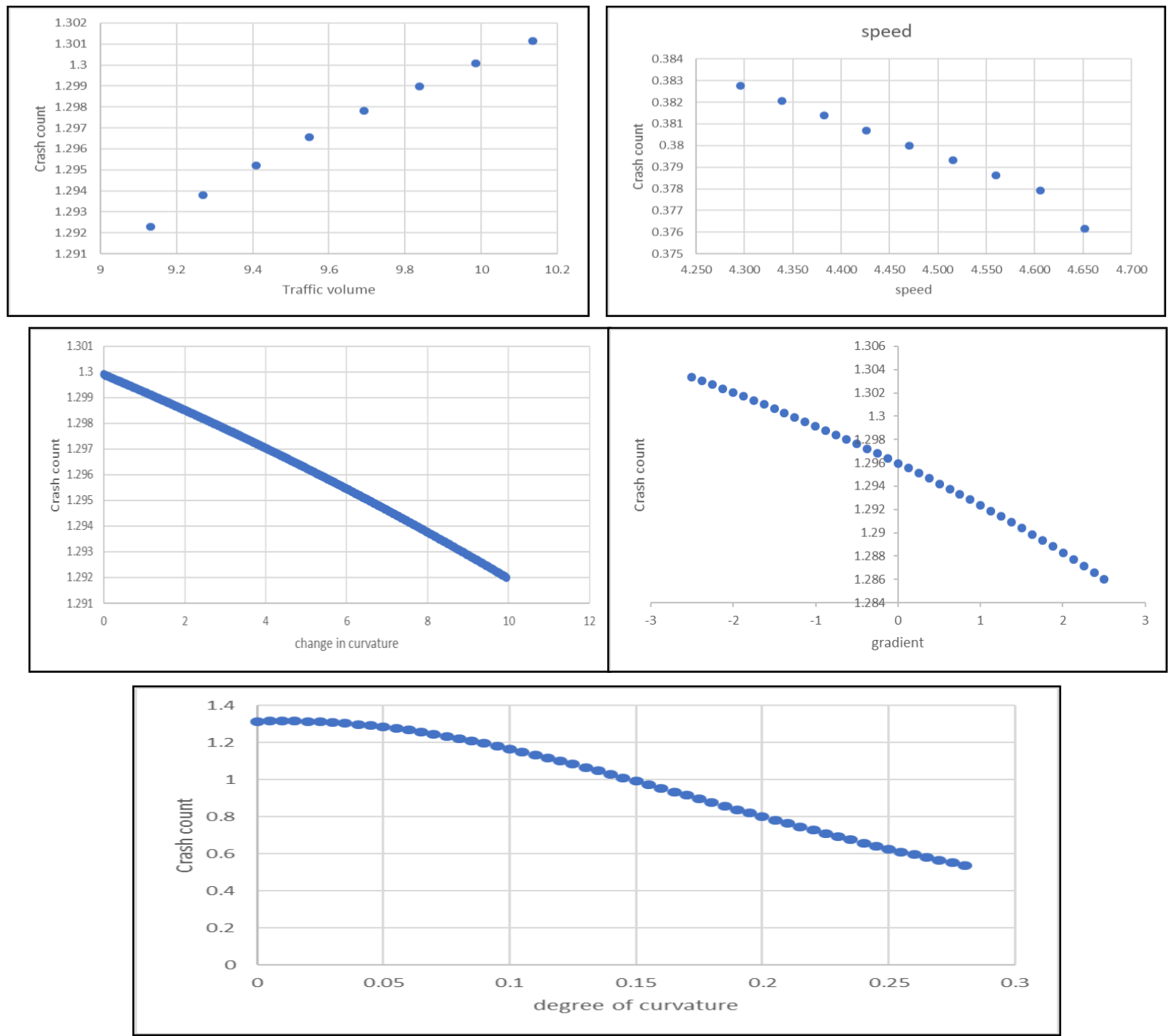

Fig. 5.2 Sensitivity Graph of Crash Count vs Traffic Volume, Speed, Change of Curvature, Gradient, Degree of Curvature for $\mathrm{NH65}$

\section{CONCLUSION}

$>$ The present area for which the analysis is done was NH-65 which is Hyderabad-Vijayawada Highway.Five years of crash data iscollected for the period of 2013- 2018 along with the crash data.The geometric parameters such as Gradient, Superelevation, Change in curvature, Degree of curvature and Traffic volume 


\section{I}

are also collected at the three toll plaza's along the strecth and speed is also collected at 30 different locations.

$>\quad$ The third networkwith bayesian regulation gives the best outpt with RMSE value as $\mathbf{0 . 2 2 1}$ and correlation coefficient value $\mathrm{R}$ as $\mathbf{0 .} 414$.

$>$ From the sensitivity graph it is clearly evident that the traffic volume is directly proportional to crash count. Remaining parameters like speed, change in curvature, Gradient, Degree of curvature are inversely proportional to the crash count.

\section{REFERENCES}

[1] Lao, Y., Wu, Y., Corey, J. and Wang, Y. (2011) Modeling Animal-Vehicle Collisions Using Diagonal Inflated Bivariate Poisson Regression. Accident Analysis and Prevention, 43, 220.

[2] Lord, D. and Mannering, F. (2010) The Statistical Analysis of Crash-Frequency Data: A Review and Assessment of Methodological Alternatives. Transportation Research Part A, 44, 291-305.

[3] Caliendo, C., Guida, M. and Parisi, A. (2007) A Crash-Prediction Model for Multilane Roads. Accident Analysis and Prevention, 39, 657-670.

[4] Park, E.-S. and Lord, D. (2007) Multivariate Poisson-Lognormal Models for Jointly Modeling Crash Frequency by Severity. Transportation Research Record, 2019, 1-6.

[5] Ma, J., Kockelman, K.M. and Damien, P. (2008) A Multivariate Poisson-Lognormal Regression Model for Prediction of Crash Counts by Severity, Using Bayesian Methods. Accident Analysis and Prevention, 40, 964-975.

[6] El-Basyouny, K. and Sayed, T. (2009) Collision Prediction Models Using Multivariate Poisson-Lognormal Regression. Accident Analysis and Prevention, 41, 820-828.

[7] Arash M. Roshandeh et al.,2016. Statistical modelling of total crash frequency athighway intersections.

[8] C.Naveenkumar et al.2011. Poisson family regression techniques for prediction ofcrash counts using Bayesian inference.

[9] Chang, L.-Y. (2005) Analysis of Freeway Accident Frequencies: Negative Binomial Regression versus Artificial Neural Network. Safety Science, 43, 541-557.

[10] Riviere, C., Lauret, P., Ramsamy, J.F.M. and Page, Y. (2006) A Bayesian Neural Network Approach to Estimating the Energy Equivalent Speed. Accident Analysis and Prevention, 38, 248-259.

[11]Xie, Y., Lord, D. and Zhang, Y. (2007) Predicting Motor Vehicle Collisions Using Bayesian Neural Networks: An Empirical Analysis. Accident Analysis and Prevention, 39, 922-933.

[12] C.Naveenkumar et al.,2014 neural network paradigms in crash modeling on non-urban highways in India.

[13] Road Accidents in India-2017.

[14] https://en.wikipedia.org/wiki/Haddon_Matrix 